DOI: $10.5216 /$ cab.v12i1.10560

\title{
SUPLEMENTAÇÃO DE VITAMINA C NA DIETA PARA LARVAS DE JUNDIÁ Rhamdia voulezi
}

\author{
Elenice Souza Reis, ${ }^{1}$ Aldi Feiden, ${ }^{2}$ Altevir Signor, ${ }^{2}$ Micheli Zaminhan, ${ }^{3}$ \\ Joana Karin FinkLeR ${ }^{4}$ e Wilson Rogério Boscolo ${ }^{2}$ \\ 1. Administradora, engenheira de pesca e mestranda em Zootecnia na área de Produção Animal pela Universidade \\ Estadual do Oeste do Paraná, Unioeste, Câmpus Toledo, PR. - E-mail: elenicesreis@yahoo.com.br \\ 2. Professores adjuntos da Universidade Estadual do Oeste do Paraná, Unioeste, Toledo, PR \\ 3. Engenheira de pesca e mestranda em Recursos Pesqueiros e Engenharia de Pesca pela Universidade Estadual do Oeste do \\ Paraná, Unioeste, Toledo, PR \\ 4. Engenheira de pesca e mestranda em Zootecnia pela Universidade Estadual do Oeste do Paraná, Unioeste, Toledo, PR
}

\section{RESUMO}

Objetivou-se com o presente estudo avaliar a suplementação de vitamina $\mathrm{C}$ na dieta para o desenvolvimento e sobrevivência de larvas de jundiá Rhamdia voulezi. Foram distribuídas, em um delineamento inteiramente casualizado, 375 larvas, em 25 aquários de $30 \mathrm{~L}$ de volume útil, na densidade de 0,5 larva/litro. As rações foram formuladas de forma a se apresentarem isoproteicas, isoenergéticas, isoaminoacídicas e isofibrosas, sendo suplementadas com 600 (controle); $850 ; 1.100 ; 1.600$ e $2.600 \mathrm{mg}$ de vitamina $\mathrm{C}$ por $\mathrm{kg}$ de ração. As larvas foram alimentadas até a saciedade aparente por um período de 31 dias, quatro vezes ao dia (8h, 11h, 14h e 17h). Mensurou-se a temperatura da água diariamente, enquanto os parâmetros físico-químicos (oxigênio dissolvido, $\mathrm{pH}$ e condutividade) foram mensurados semanalmente. Não observaram-se diferenças significativas no desempenho das larvas em relação ao peso médio final, comprimento médio final, fator de condição, taxa de crescimento específico e sobrevivência. Conclui-se que o desempenho e a sobrevivência de larvas de jundiá Rhamdia voulezi não são influenciados pela suplementação em níveis superiores a 600 mg de vitamina C por kilograma de dieta.

PALAVRAS-CHAVES: Espécie nativa, nutrição, vitamina C.

\section{ABSTRACT}

\section{SUPPLEMENTATION WITH VITAMIN C IN THE DIET FOR Rhamdia Voulezi LARVAE}

The aim of this study was to evaluate the supplementation of vitamin $\mathrm{C}$ in the diet on the development and survival of catfish larvae Rhamdia voulezi. 375 larvae were distributed in a completely randomized design in aquariums $30 \mathrm{~L}$ of volume, density of 0.5 larvae per liter. The diets were formulated to make isonitrogenous, isoenergetic, isoaminoacid and isofibrosas, and supplemented with 600 (control), 850, 1100, 1600 and $2600 \mathrm{mg}$ vitamin C per $\mathrm{kg}$ feed.

KEYWORDS: Native species, nutrition, vitamin C.
The larvae were fed to apparent satiation for a period of 31 days, four times a day $(8 \mathrm{~h}, 11 \mathrm{~h}, 14 \mathrm{~h}$ and $17 \mathrm{~h})$. The water temperature was measured daily, while the physical-chemical parameters (dissolved oxygen, $\mathrm{pH}$ and conductivity) were measured weekly. Not observed significant differences in performance of larvae in relation to the final weight, final length, condition factor, specific growth rate and survival. We conclude that the performance and survival of catfish larvae Rhamdia voulezi are not influenced by supplementation at levels above $600 \mathrm{mg}$ vitamin $\mathrm{C}$ per kilogram of diet. 


\section{INTRODUÇÃO}

O jundiá Rhamdia voulezi é uma espécie endêmica da bacia do rio Paraná, pertence à classe dos Osteichtyes, série Teleostei, ordem dos Siluriformes, e à família Heptapteridae. De acordo com BALDISSEROTTO \& RADUNZ-NETO (2005), jundiá é o nome comum dado aos peixes pertencentes ao gênero Rhamdia. Os bagres desse gênero apresentam hábito alimentar onívoro, facilidade de criação e boa aceitação pelos consumidores (GOMES et al., 2000).

REIDEL (2007) afirma que inúmeras são as vantagens da criação de espécies de peixes nativos quando comparadas às exóticas, pois essas se encontram adaptadas ao clima, alimentando-se em temperaturas mais baixas. Para o bom desempenho das suas funções metabólicas, imunológicas e reprodutivas, os peixes precisam de uma alimentação balanceada em nutrientes, minerais e vitaminas. Assim, fazem-se necessários estudos para identificar essas necessidades, de forma a elaborar dietas que atendam às exigências de cada espécie, nas diferentes fases de vida.

Vitaminas são compostos orgânicos distintos dos aminoácidos, carboidratos e lipídios, e são necessárias em quantidades traços a partir de fontes exógenas, para o crescimento normal (HALVER, 1989). São classificadas em hidrossolúveis e lipossolúveis, sendo oito hidrossolúveis exigidas em quantidades relativamente pequenas. Estas têm a função principal de atuar como coenzima; as mais conhecidas as do complexo B. Três vitaminas hidrossolúveis são necessárias em maior quantidade: vitamina $\mathrm{C}$, inositol e colina, que têm outras funções além de coenzimas. As vitaminas A, D, E e K são lipossolúveis e apresentam funções independentes das enzimas ou, em alguns casos, como a vitamina K, podem ter papel de coenzima (NRC, 1993).

As vitaminas são exigidas em pequenas quantidades para crescimento normal, reprodução, saúde e metabolismo dos peixes (MIRANDA et al., 2003). A vitamina $\mathrm{C}$ é essencial para a maioria das espécies de teleósteos, os quais não têm a capacidade de sintetizá-la a partir de outras substâncias, pois não possuem a enzima gulonolactona oxidase. Portanto, a vitamina C precisa ser adicionada à dieta, e a principal forma utilizada é o ácido ascórbico.

A vitamina $\mathrm{C}$ atua no organismo como cofator para diversas reações, dentre elas, a hidroxilação da prolina na síntese de colágeno, a hidroxilação do triptofano para 5-hidroxitriptofano e a conversão do 3,4-dihidroxiphenilpiruvato para noraepinefrina (BAKER, 1967). HALVER (1972) indicou alguns sintomas clássicos de deficiência de vitamina $\mathrm{C}$ em peixes: o deslocamento da coluna (lordose e escoliose), a deficiência na formação de colágeno e a distorção do suporte da cartilagem. Também segundo NRC (1993), o ácido ascórbico é essencial para a síntese de colágeno, a formação de cartilagem, dentes e ossos e a cicatrização do tecido epitelial.

Um dos maiores problemas das espécies nativas é o início de seu desenvolvimento, quando ocorrem mortalidades em taxas elevadas. Devido à importante participação da vitamina $\mathrm{C}$ no metabolismo, acredita-se que sua suplementação na dieta pode melhorar as características de desempenho e sobrevivência das larvas de peixes (LOVELL, 1998), pois essa vitamina tem função importante na formação de colágeno, que é o principal componente do esqueleto (ROTTA, 2003).

A fase de larvicultura dos peixes caracteriza-se pela rápida depleção das reservas de ácido ascórbico durante o desenvolvimento. O metabolismo da larva é excepcionalmente maior nessa fase, sugerindo que as exigências da vitamina $C$ sejam maiores que nos estágios posteriores (TOYAMA et al., 2000).

Dessa forma, objetivou-se com o presente trabalho avaliar a suplementação de vitamina $\mathrm{C}$ no desempenho e sobrevivência de larvas de jundiás Rhamdia voulezi.

\section{MATERIAL E MÉTODOS}

O experimento foi realizado no Laboratório de Aquicultura da Unioeste, Câmpus Toledo, PR, durante 31 dias, nos meses de janeiro e fevereiro de 2009. Utilizaram-se 375 larvas de jundiá Rhamdia voulezi com 48 horas após a eclosão, peso inicial médio de 2,8 $\pm 0,7 \mathrm{mg}$ e comprimento total de $5,4 \pm 0,6 \mathrm{~mm}$, quando as larvas apresentavam abertura da boca e início da alimentação exógena. As instalações experimentais possuíam 25 unidades de criação, com capacidade para $30 \mathrm{~L}$ cada uma, em um delineamento inteiramente casualisado com cinco tratamentos e cinco repetições, sendo que a unidade experimental foi composta por um aquário com quinze larvas. As larvas foram obtidas por 
meio de reprodução induzida de matrizes cultivadas em tanques-redes, instalados no reservatório da usina hidrelétrica Governador José Richa, no rio Iguaçu, município de Boa Vista da Aparecida, PR.

As dietas experimentais foram isoproteicas (45\% de proteína bruta) e isoenergéticas $(3.800 \mathrm{kcal}$ de energia digestível $/ \mathrm{kg}$ ), formuladas com os mesmos ingredientes (Tabela 1), variando apenas os níveis de vitamina C: 600 (controle); 850; 1.100; 1.600 e 2.600 $\mathrm{mg}$ de vitamina $\mathrm{C} / \mathrm{kg}$ de ração. O primeiro nível de vitamina $\mathrm{C}(600 \mathrm{mg} / \mathrm{kg})$ foi suprido pelo suplemento mineral e vitamínico utilizado. Os outros níveis foram conseguidos através da suplementação com vitamina $\mathrm{C}$ monofosfatada com $35 \%$ de pureza.

TABELA 1. Composição em ingredientes (\% matéria natural) e composição nutricional da ração basal

\begin{tabular}{lrlr}
\hline Ingredientes & $(\%)$ & Nutrientes & $(\%)$ \\
\hline Farelo de soja & 36,12 & Cálcio & 2,37 \\
Farinha de peixe & 27,51 & Energia digestível & $3.800 \mathrm{kcal} / \mathrm{kg}$ \\
Farinha de vísceras & 20,00 & Fibra bruta & 2,52 \\
Óleo de soja & 11,47 & Fósforo total & 1,50 \\
Hidrolisado de fígado & 3,00 & Gordura & 16,00 \\
Suplemento (min+vit) & 1,00 & Histidina & 1,04 \\
Fosfato bicálcio & 0,56 & Lisina total & 2,81 \\
Sal comum & 0,30 & Metionina + cistina & 1,55 \\
Antioxidante (BHT) & 0,02 & Metionina total & 0,94 \\
& & Proteína bruta & 45,00 \\
Total & & Treonina total & 1,88 \\
\end{tabular}

${ }^{1}$ Níveis de garantia por kg do produto Premix (DSM-Roche®): vit. A, 24.000 UI; vit. D3, 6.000 UI; vit. E, 300 mg; vit. K3, 30 mg; vit. B1, 40 mg; vit. B2, $40 \mathrm{mg}$; vit. B6, $35 \mathrm{mg}$; vit. B12, $80 \mathrm{mg}$; ác. fólico, $12 \mathrm{mg}$; pantotenato Ca, $100 \mathrm{mg}$; vit. C, $600 \mathrm{mg}$; biotina, $2 \mathrm{mg}$; colina, $1.000 \mathrm{mg}$; niacina; ferro, $200 \mathrm{mg}$; cobre, $35 \mathrm{mg}$; manganês, $100 \mathrm{mg}$; zinco, $240 \mathrm{mg}$; iodo, 1,6 mg; cobalto, 0,8 mg.

Os alimentos para fabricação das rações foram inicialmente moídos em um triturador tipo martelo com peneira de $0,5 \mathrm{~mm}$. Após a moagem, os ingredientes foram peneirados, pesados e misturados, incorporando o suplemento mineral e vitamínico. Realizou-se a suplementação dos níveis de vitamina $\mathrm{C}$ diluindo-se a quantidade a ser fornecida na dieta em uma pequena fração da mistura e posteriormente homogeneizando-a com a dieta completa, o que resultou na ração farelada fornecida às larvas de $R$. voulezi do experimento.

Na primeira semana de experimento, alimentaram-se as larvas com Artemia sp. Os microcrustáceos foram produzidos no Laboratório de Aquicultura através da eclosão de cistos. Após uma semana, a ração foi fornecida em conjunto com os náuplios de artêmia, quatro vezes ao dia (8h, 11h, 14h e 17h), até a saciedade aparente. A partir do $15^{\circ}$ dia até o final do experimento, somente as rações experimentais foram fornecidas às larvas. O processo de substituição da artêmia por ração foi gradativo, para que as larvas se adaptassem ao manejo alimentar.

Os aquários possuíam sistema de aeração individual. Antes da última alimentação, eles foram sifonados para a remoção de excretas dos peixes e sobras de alimentos, retirando-se deles $40 \%$ do volume de água.

Mensurou-se a temperatura da água diariamente, pela manhã ( $8 \mathrm{~h} 30$ min.) e à tarde (17h). Os parâmetros físico-químicos $(\mathrm{pH}$, oxigênio dissolvido $[\mathrm{mg} / \mathrm{L}]$ e a condutividade elétrica $[\mu \mathrm{s} / \mathrm{cm}]$ ) foram verificados semanalmente, utilizando-se medidores portáteis.

Ao final do período experimental, os peixes foram mantidos em jejum por 24 horas. Depois, os animais foram insensibilizados até a morte com 
benzocaína na concentração de $250 \mathrm{mg} / \mathrm{l}$ e tiraram-se as medidas individuais de peso (mg) e comprimento total $(\mathrm{mm})$ de cada peixe em cada uma das unidades experimentais. Foram avaliados o comprimento final médio (CF), o peso final médio (PF), sobrevivência (SO), taxa de crescimento específico (TCE) e fator de condição de Fulton (FC) dos animais.

A taxa de crescimento específico foi calculada através da fórmula TCE $=[(\ln \mathrm{PF}-\ln \mathrm{PI}) / \mathrm{T}] \times 100$, em que PF é o peso final (g), PI é o peso inicial (g) e T é o tempo em dias (HOUDE, 1989).

A relação entre o peso e o comprimento corporal permite calcular um parâmetro que determina o grau de bem-estar do peixe, o que se chama de fator de condição. Dessa forma, nutrição, doenças e contaminantes são altamente inter-relacionados com a criação do animal. $\mathrm{O}$ aporte nutricional insuficiente pode alterar o fator de condição, conforme RATZ \& LLORET (2003). A estimativa do fator de condição pode ser feita através do fator de condição de Fulton e do fator de condição alométrico. Segundo o fator de condição de Fulton, a relação peso-comprimento é isométrica (ROCHA et al., 2005).

O fator de condição de Fulton foi calculado pela seguinte fórmula:

$\mathrm{FC}=\mathrm{W} / 1^{3}$

em que:

$\mathrm{FC}=$ fator de condição de Fulton,

$\mathrm{W}=$ peso corporal $(\mathrm{g})$,

$1=$ comprimento corporal total $(\mathrm{cm})$.

Submeteram-se os dados ao teste de homogeneidade e normalidade da análise de variância (ANOVA) pelo programa estatístico SAS (SAS INSTITUTE, 2004), No nível de 5\% de significância.

\section{RESULTADOS E DISCUSSÃO}

A temperatura da água dos aquários experimentais foi de $25,9 \pm 1,40{ }^{\circ} \mathrm{C}$, valor inserido na faixa ideal para criação de peixes tropicais, de acordo com PROENÇA \& BITTENCOURT (1994). FRACALOSSI et al. (2002) afirmam que o conforto térmico para jundiás se encontra entre 18,0 e $28,0^{\circ} \mathrm{C}$. PIEDRAS et al. (2004), em trabalho com juvenis de jundiá $R$. quelen (peso médio de $24,6 \mathrm{~g}$ ) para avaliar o crescimento em diferentes temperaturas da água $\left(20,23\right.$ e $\left.26^{\circ} \mathrm{C}\right)$, concluíram que a espécie apresenta maior ganho de peso $(41,4 \mathrm{~g})$ na temperatura de $23,7^{\circ} \mathrm{C}$.

O oxigênio dissolvido, o $\mathrm{pH}$ e a condutividade elétrica foram de 4,74 $\pm 0,71 \mathrm{mg} \mathrm{L}^{-1}, 7,97 \pm 0,18$ e $0,14 \pm 0,06 \mu \mathrm{S} \mathrm{cm}^{-1}$, respectivamente. BRAUN (2005) recomenda para melhor crescimento dos jundiás, valores acima de 4,3 $\mathrm{mg} \mathrm{L}^{-1}$ de oxigênio dissolvido. MAFFEZZOLLI \& NUÑER (2006) realizaram experimento com alevinos de jundiá $R$. quelen em diferentes concentrações de oxigênio dissolvido (1,3; 2,4; 3,7; 5,4 e 7,5 mg O $\left.\mathrm{m} \mathrm{mg} \mathrm{L}^{-1}\right)$, observando que o aumento da concentração desse elemento na água proporcionou maior aumento de peso e comprimento.

$\mathrm{O}$ pH de 7,97 encontrado neste estudo está dentro da faixa recomendada para juvenis de jundiá $R$. quelen, que é de 4,0 a 9,0 em águas moles, de acordo com BALDISSEROTTO \& RADUNZ-NETO (2005). Experimento relativo à influência do $\mathrm{pH}$ sobre o desenvolvimento de larvas de jundiá $R$. quelen mostrou que o melhor crescimento é obtido com pH de 8,0 a 8,5 (LOPES \& BALDISSEROTTO, 2002).

Não foram observadas diferenças nos tratamentos $(\mathrm{P}>0,05)$ em relação às médias de peso final, comprimento final, fator de condição, taxa de crescimento específico e taxa de sobrevivência (Tabela 2), indicando que a suplementação de vitamina $\mathrm{C}$ nos níveis utilizados não afetou os parâmetros de desempenho analisados.

Como a ração basal formulada para este experimento já continha suplemento mineral e vitamínico, possivelmente o tratamento que não recebeu suplementação (controle), e que apresentava $600 \mathrm{mg}$ de vitamina $\mathrm{C} / \mathrm{kg}$ de ração, atendeu às exigências das larvas de jundiá $R$. voulezi nesse aspecto. Assim, os peixes do tratamento controle desenvolveram-se em condições normais, tendo à sua disposição a concentração necessária de vitamina $\mathrm{C}$ para seus processos metabólicos.

TROMBETTA et al. (2006), em experimento para avaliar a suplementação vitamínica no desenvolvimento de larvas de jundiá $R$. quelen, observaram que a ausência de mistura vitamínica na ração reduz a sobrevivência e o crescimento das larvas. Para esses autores, a mistura vitamínica que obteve melhores resultados continha $5.000 \mathrm{mg} / \mathrm{kg}$ de ração de vitamina C, proporcionando peso final de 157,7 mg após 21 dias. No presente experimento, após 31 dias obteve-se peso final entre 290 e $380 \mathrm{mg}$. 
TABELA 2. Parâmetros de desempenho de larvas de jundiá $R$. voulezi alimentadas com rações suplementadas com vitamina C

\begin{tabular}{cccccccc}
\hline \multicolumn{7}{c}{ Níveis de suplementação de vitamina C (mg/kg de ração) } \\
\hline Parâmetros & 600 (controle) & 850 & 1.100 & 1.600 & 2.600 & $\mathrm{~F}(\mathrm{p})$ & $\mathrm{CV}(\%)$ \\
\hline PF $(\mathrm{g})$ & 0,36 & 0,38 & 0,29 & 0,30 & 0,32 & $1,49(0,24)$ & 26,16 \\
CT $(\mathrm{cm})$ & 3,31 & 3,46 & 3,14 & 3,22 & 3,21 & $1,58(0,22)$ & 9,98 \\
FC & 0,98 & 0,93 & 0,92 & 0,88 & 0,96 & $1,10(0,38)$ & 7,04 \\
TCE (\%) & 15,59 & 15,86 & 14,75 & 14,97 & 15,24 & $1,05(0,41)$ & 6,43 \\
SO (\%) & 73,33 & 78,67 & 76,00 & 76,00 & 81,33 & $0,25(0,91)$ & 18,95 \\
\hline
\end{tabular}

$\mathrm{PF}=$ peso final $(\mathrm{g}) \mathrm{CF}=$ comprimento total $(\mathrm{cm}) ; \mathrm{FC}=$ fator de condição; $\mathrm{TCE}=$ taxa de crescimento específico; $\mathrm{SO}=$ sobrevivência (\%) e CV = coeficiente de variação.

Observou-se que não houve sinais de deficiência nos peixes alimentados com as rações contendo menor suplementação de vitamina C. MELLO et al. (1999), ao avaliarem o crescimento e a sobrevivência de alevinos de piauçu Leporinus obtusidens suplementados com diferentes níveis $(0,50,150,250,350,450,550,650$, 750 e $850 \mathrm{mg}$ ) de vitamina $C$ na dieta, também não detectaram sinais de deficiência desse componente, como lordose e escoliose.

BORBA et al. (2007) analisaram a resistência à ictiofitiríase (Ichthyophthirius multifilis) do jundiá $R$. quelen alimentado com diferentes níveis de vitamina $\mathrm{C}$ $(0,250,500,1.000$ e $2.000 \mathrm{mg} / \mathrm{kg}$ de ração). Os autores não observaram efeito significativo das concentrações de vitamina $\mathrm{C}$ na dieta com relação ao crescimento e à sobrevivência dos alevinos de jundiá.

Em experimento que avaliou o ganho de peso e a taxa de sobrevivência de pós-larvas de pacu (Piaractus mesopotamicus) alimentadas com rações contendo diferentes níveis de vitamina C, MIRANDA et al. (2003) concluíram que a suplementação de $250 \mathrm{mg}$ de vitamina $\mathrm{C} / \mathrm{kg}$ de ração, na forma de 2-monofosfato de ácido ascórbico L, apresentou-se como a mais indicada para a fase pós-larval desse peixe.

$\mathrm{Na}$ análise do fator de condição, a dieta contendo $600 \mathrm{mg}$ de vitamina $\mathrm{C} / \mathrm{kg}$ de ração obteve a maior média $(0,98)$, que não diferiu significativamente, contudo, dos demais níveis. PEIL et al. (2007) observaram que o fator de condição de pós-larvas de jundiá $R$. quelen alimentadas com dietas contendo 0, 3.000, 9.000 e 15.000 UI de vitamina A por quilo de ração também não apresentou diferença entre os tratamentos, com valores oscilando entre
0,86 e 0,94 .

No presente experimento, a taxa de crescimento específico teve valores entre $14,75 \%$ e 15,86\%, porém, sem diferenças significativas $(\mathrm{P}>0,05)$ entre os tratamentos. TROMBETTA et al. (2006), em estudo que avaliaou a suplementação vitamínica para larvas de jundiá $R$. quelen, obtiveram melhores TCE (18,5\% e $19,7 \%$ ) para os tratamentos que continham $5.000 \mathrm{mg}$ de vitamina $\mathrm{C} / \mathrm{kg}$ de dieta.

Os resultados do presente trabalho podem ter sido influenciados pela disponibilidade de vitamina C no tratamento controle $(600 \mathrm{mg} / \mathrm{kg}$ de ração) e pela perda dos nutrientes para a água por lixiviação, já que a vitamina $\mathrm{C}$ utilizada não tinha proteção contra esse processo.

A sobrevivência das larvas de jundiá $R$. voulezi neste experimento variou de $73,33 \%$ a $81,33 \%$, sem diferença significativa entre os tratamentos. A maior média, de $81,33 \%$, foi obtida com a suplementação de $2.600 \mathrm{mg}$ de vitamina $\mathrm{C} / \mathrm{kg}$ de ração. TROMBETTA et al. (2006), ao avaliarem a suplementação vitamínica para larvas de jundiá $R$. quelen, observaram sobrevivência de $87,3 \%$ com a mistura vitamínica que continha $5.000 \mathrm{mg}$ de vitamina $\mathrm{C} /$ $\mathrm{kg}$ de ração. Portanto, o presente experimento demonstra que a concentração de $600 \mathrm{mg}$ de vitamina $\mathrm{C} / \mathrm{kg}$ de dieta é adequada para manter um bom desenvolvimento das larvas.

\section{CONCLUSÃO}

O desempenho e a sobrevivência de larvas de jundiá Rhamdia voulezi não são influenciados pela suplementação em níveis superiores a $600 \mathrm{mg}$ de vitamina $\mathrm{C}$ por kilograma de dieta. 


\section{AGRADECIMENTOS}

Ao Grupo de Estudo em Manejo na Aquicultura (GEMAq), pela estrutura disponibilizada. À Secretaria de Ciência Tecnologia e Ensino Superior (SETI) Fundo Paraná.

\section{REFERÊNCIAS}

BALDISSEROTTO, B.; RADUNZ NETO, J. Jundiá (Rhamdia sp). In: BALDISSEROTTO, B.; GOMES, L. C. Espécies nativas para piscicultura no Brasil. Santa Maria: UFSM, 2005. p. 303-325.

BAKER, E. M. Vitamin C requirements in stress. American Journal of Clinical Nutrition, v. 20, n. 6, p. 583-90, 1967.

BORBA, M. R.; FRACALOSSI, D. M.; FREITAS, F. A. Efeito da suplementação de vitamina $\mathrm{C}$ na dieta sobre a susceptibilidade de alevinos de jundiá, Rhamdia quelen, ao Ichthyophthirius multifilis. Acta Scientiarum. Animal Sciences, Maringá, v. 29, n. 1, p. 93-99, 2007.

BRAUN, A. S. Biologia reprodutiva e identificação do uso de lagoa marginal como sítio de reprodução para espécies dominantes da ictiofauna da lagoa do Casamento, sistema nordeste da laguna de Patos, RS. 2005. 145 f. Tese (Doutorado)- Pontifícia Universidade Católica do Rio Grande do Sul, 2002. Disponível em: $<$ http://www.dominiopublico.gov.br/pesquisa/DetalheObraForm. do? select action $=\&$ co obra $=143321>$. Acesso em: $1^{\circ}$ jul. 2010.

FRACALOSSI, D. M.; ZANIBONI FILHO, E.; MEURER, S. No rastro das espécies nativas. Panorama da Aquicultura, v. 12, p. 4.349, 2002.

GOMES, L. C.; GOLOMBIESKI, J. I.; GOMES, A. R. C.; BALDISSEROTTO, B. Biologia do jundiá Rhamdia quelen (Teleostei, Pimelodidae). Ciência Rural, v. 30, n. 1, p. 179-185, 2000 .

HALVER, J. E. The role of ascorbic acid in fish disease and tissue repair. Bulletin of the Japanese Society of Science Fisheries, v. 38, n. 1, p. 79-92, 1972.

HALVER, J. E. Fish nutrition. 2. ed. San Diego: Academic Press, 1989. $798 \mathrm{p}$.

HOUDE, E. D. Comparative growth, mortality, and energetics of marine fish larvae: temperature and implied latitudinal effects. U.S. Fishery Bulletin, v. 87, p. 471-495, 1989.

LOPES, J. M.; BALDISSEROTTO, B. Survival and growth of silver catfish larvae exposed to different water $\mathrm{pH}$. Aquaculture International, v. 9, p. 73-80, 2002.
LOVELL, T. Nutrition and feeding of fish. 2. ed. Norwell: Kluwer Academic Publishers, 1998. 267 p.

MAFFEZZOLLI, G.; NUÑER, A. P. O. Crescimento de alevinos de jundiá, Rhamdia quelen (Pisces, Pimelodidae), em diferentes concentrações de oxigênio dissolvido. Acta Scientiarum Biology, v. 28 , n. 1, p. 41-45, 2006.

MELLO, R. F.; MOURA, M. A. M.; VIEIRA, I.; CYRINO, J. E. P. Suplementação de dietas de alevinos de Piauçu (Leporinus obtusidens) com vitamina C. Scientia Agrícola, v. 56, n. 4, p. 1.223-1.231, 1999.

MIRANDA, E. C.; PINTO, L. G. Q.; FURUYA, W. M.; PEZZATO, L. E.; BARROS, M. M.; PEZZATO, A. C. Ganho de peso e taxa de sobrevivência de pós-larvas de pacu (Piaractus mesopotamicus) alimentadas com rações contendo diferentes níveis de vitamina $\mathrm{C}$. Acta Scientiarum. Animal Sciences, v. 25, n. 1, p. 31-36, 2003.

NRC. NATIONAL RESEARCH COUNCIL. Nutrients requeriments of fish. Washington: National Academy, 1993. 114 p.

PEIL, S. Q.; POUEY, J. L. O. F.; LOPES, P. R. S.; MARTINS, C. R.; TIMM, G. Adição de vitamina A na dieta de pós-larvas de jundiá (Rhamdia quelen). Biodiversidade Pampeana, v. 5, n. 1, p. 9-15, 2007.

PIEDRAS, S. R. N.; MORAES, P. R. R.; POUEY, J. L. O. F. Crescimento de juvenis de jundiá Rhamdia quelen de acordo com a temperatura da água. Boletim Instituto de Pesca, v. 30, n. 2, p. 177-182, 2004.

PROENÇA, C. E. M.; BITTENCOURT, P. R. L. Manual de piscicultura tropical. Brasília: Ibama, 1994. 196 p.

RATZ, H. J.; LLORET, J. Variation in fish condition between atlantic cod (Gadus morhua) atocks the effect on their productivity and management implications. Fisheries Research, v. 60, p. 369-380, 2003.

REIDEL, A. Níveis de energia e proteína na alimentação de alevinos de jundiá (Rhamdia quelen) criados em tanques-rede. 2007, 76 f. Tese (Doutorado em Aquicultura) - Universidade Estadual Paulista, 2007. Disponível em: $<$ http://www.caunesp. unesp.br/Publicacoes/Dissertacoes_Teses/Teses/Tese $\% 20$ Adilson\%20Reidel.pdf>. Acesso em: 2 fev. 2011.

ROCHA, M. A.; RIBEIRO, E. L. A.; MIZUBUTI, I. Y.; SILVA, L. D. F.; BOROSKY, J. C.; RUBIN, K. C. P. Uso do fator de condição alométrico e de fulton na comparação de carpa (Cyprinus carpio), considerando os sexos e idade. Semina: Ciências Agrárias, v. 26, n. 3, p. 429-434, jul.-set. 2005.

ROTTA, M. A. Utilização do ácido ascórbico (vitamina C) pelos 
peixes. 2003. Boletim Técnico Embrapa Pantanal, Corumbá. 54 p. Disponível em: $<$ http://www.cpap.embrapa.br/publicacoes/online/ DOC49.pdf $>$. Acesso em: 2 fev. 2011.

SAS INSTITUTE. SAS user's guide statistics. 9. Ed. Cary, North Caroline: SAS Institute Inc., 2004.

TOYAMA, G. N.; CORRENTE, J. E.; CYRINO, J. E. P.
Suplementação de vitamina $\mathrm{C}$ na reversão sexual de tilápia do Nilo (Oreochromis niloticus). Scientia Agricola, v. 57, n. 2, p. 221-228, abr.-jun. 2000.

TROMBETTA, C. G.; RADUNZ NETO, J.; LAZZARI, R. Suplementação vitamínica no desenvolvimento de larvas de Jundiá (Rhamdia quelen). Ciência e Agrotecnologia, v. 30, n. 6, p. 1.224-1.229, 2006.

Protocolado em: 23 jul. 2010. Aceito em: 17 jan. 2011. 